\title{
Relative abundance of big and little gastrins in the tumours and blood of patients with the Zollinger- Ellison syndrome
}

\author{
GRAHAM J. DOCKRAY ${ }^{1}$, JOHN H. WALSH ${ }^{2}$, AND EDWARD PASSARO, JR \\ From the VA Wadsworth Hospital Center and UCLA School of Medicine, Los Angeles, Ca, USA
}

SUMMARY The relative concentrations of big gastrin (G-34) and little gastrin (G-17) were compared in the sera and tumours (gastrinomas) of Zollinger-Ellison syndrome patients. Big and little gastrins were identified in all 10 serum samples and in all 10 tumour biopsies examined. In serum, G-34 (range of concentrations $58-220000 \mathrm{fmol} / \mathrm{ml}$ ) was the major form of gastrin and G-17 (22-78 000 $\mathrm{fmol} / \mathrm{ml})$ was a minor component; the mean relative abundance of $\mathrm{G}-17$ (G17/[G17 + G34]) in serum was $0 \cdot 18$ and the mean relative abundance of G-34 was $0 \cdot 82$. In tumour, however, the opposite was true: G-17 (49-869 $000 \mathrm{pmol} / \mathrm{g})$ was the major component and G-34 (45-464 pmol/g) a minor component, and the relative proportions of $\mathrm{G}-17$ and G-34 were 0.73 and 0.27 respectively. Following an intravenous injection of porcine secretin $(2.0 \mathrm{U} / \mathrm{kg})$ there was a rapid increase in concentration of all forms of gastrin in the blood, but the increase in G-17 was proportionately greater than that of G-34 (relative abundance of G-17 in basal serum was 0.21 compared with 0.37 , five minutes after secretin). Differences in the half lives of G-17 and G-34 may partly explain their relative abundancies in serum and tumour tissue.

Gastrin was originally isolated from tumours of Zollinger-Ellison (ZE) patients in the form of a pair of heptadecapeptides (G-17) which differed only in the presence (G-17-II) or absence of a sulphate group (G-17-I) (Gregory, Tracy, Agarwal, and Grossman, 1968). Recently, Yalow and Berson (1970a) showed that the main circulating form of gastrin in ZE patients was larger and less acidic than G-17 and they called this 'big' or 'basic' gastrin. It is now known that big gastrin is a molecule of 34 amino acids (G-34) of which the C-terminal heptadecapeptide is identical to G-17, and like G-17 it exists in both unsulphated (G-34-I) and sulphated (G-34-II) states (Gregory and Tracy, 1972). Other molecular forms of gastrin have also been identified, including 'minigastrin', a peptide corresponding to the C-terminal tridecapeptide of G-17 (Gregory, 1974; Rehfeld and Stadil, 1973) and an amino

\footnotetext{
${ }^{1}$ Present address : Department of Physiology, University of Liverpool, Liverpool L69 3BX, England.

2Please address correspondence to: Dr John H. Walsh, VA Wadsworth Hospital Center, Building 115 Room 115, Los Angeles, California 90073.

Received for publication 11 February 1975.
}

terminal fragment of G-17, possibly 1-13 G-17 (Dockray and Walsh, 1974). In addition, two molecules which are larger than G-34 have been described but not yet chemically characterized; these are the 'big, big' gastrin of Yalow and Berson (1972) and component I of Rehfeld and Stadil (1973). All these different forms of gastrin have been identified in extracts of normal hog antral mucosa.

It has recently been shown that with potencies expressed in terms of serum concentration ('endogenous dose') required for a given biological response, then G-17 was about six times more potent than G-34 in stimulating gastric acid secretion in dogs (Walsh, Debas, and Grossman, 1974). However, the clearance rate of G-34 was about five times less than that of G-17 so that when the relative potency of the two peptides was described in terms of exogenous dose G-34 appeared slightly more potent than G-17. The clearance rate of G-13 was approximately equal to that of G-17 and this form of gastrin had about $40 \%$ the potency of G-17 when either exogenous or endogenous doses were compared (Debas, Walsh, and Grossman, 1974). Amino terminal fragments of G-17 have no known biological activity and nothing is yet known of the 353 
biological properties of big big gastrin and component $\mathrm{I}$.

At present little is known of the significance of the heterogeneity of gastrins, but since there are marked differences in their biological activities the factors which govern their relative abundance in serum are of obvious importance. Hitherto there have been only limited attempts to relate quantitatively concentrations of the molecular forms of gastrin in circulation and tissues. In the present study we have compared the concentrations of the two principal biologically active forms of gastrin (G-34 and G-17) in serum and tumours of patients with gastrinoma.

\section{Materials and Methods}

Studies were carried out on serum and tumour samples collected from a total of 13 patients. In 10 of the patients the diagnosis was established on the basis of islet cell tumours which contained immunoreactive gastrin, and in the remaining patients the diagnosis was based on an elevated serum gastrin concentration and anomalous response to secretin (Isenberg, Walsh, Passaro, Moore, and Grossman, 1972). Sera were obtained from 10 patients in a basal state after an overnight fast; in eight of these patients serum was also taken at intervals of time after a rapid intravenous injection of $2.0 \mathrm{U} / \mathrm{kg}$ pure natural porcine secretin (Gastrointestinal Hormone Research Unit, Karolinska Institutet, Stockholm, Sweden). Biopsies of gastrinoma tissue were obtained from 10 patients at surgery and immediately placed on solid $\mathrm{CO}_{2}$. For seven of these patients serum samples had been previously obtained, but in three cases no serum samples were available for study. Tumour biopsies were transported to the laboratory and were either immediately extracted in boiling water or deep frozen. In the case of tissues which were extracted straight away, the longest delay between taking the biopsy and extracting it was 20 minutes; in most cases the time elapsed was 10 to 15 minutes. Frozen tissue was stored at $-20^{\circ}$ for up to three months before extraction. All tissues were thinly sliced and extracted in boiling water $(10 \mathrm{mg}$ tissue $/ \mathrm{ml})$ for five minutes. The extract was then shaken at room temperature for 20 to 30 minutes and centrifuged $(2000 \times g$, five $\min )$ and the supernatant fluid stored at $-20^{\circ}$ before analysis of gastrin. Repeated extraction of the pellet from a single tumour extract indicated that about $97 \%$ of the total gastrin immunoreactivity was recovered in the first extract. The addition of ${ }^{125}$ I G-34.to the extract at the time of extraction and subsequent gel filtration of extract on Sephadex G50 did not indicate any conversion of G-34 to smaller molecular forms.
The molecular forms of gastrin in the serum and tumour extracts were separated by gel filtration on columns of Sephadex G50 superfine $(1 \times 100 \mathrm{~cm})$. Columns were equilibrated and eluted with $0.02 \mathrm{M}$ sodium barbital buffer, $\mathrm{pH} 8 \cdot 4$, containing sodium azide $0.2 \mathrm{~g} / \mathrm{l}$, and run at $4^{\circ}$. The columns were calibrated with the following pure peptides isolated by Professor R. A. Gregory and Dr H. T. Tracy from gastrinomas: G-34-I and -II, G-17-I and -II, and G-13-I. All samples were applied to the columns together with $0.5 \mathrm{fmol}$ of monoiodinated ${ }^{125}$ I G-17-I as marker. The serum protein peak in the column eluates was detected by absorbence at $280 \mathrm{~nm}$, and the salt peak was detected by conductivity. When tumour extracts were chromatographed, $0.1 \mathrm{ml}$ normal human serum was added to the solution before application to the column to provide markers for salt and protein peaks. The fraction number of the eluates is described in terms of percentage eluation volume from protein $(0 \%)$ to salt peaks $(100 \%)$. Recovery of gastrin applied to the columns varied from 60 to $150 \%$ and in the majority of experiments was in the region of $90 \%$.

Radioimmunoassay of gastrin in the unfractionated samples and the Sephadex column eluates was carried out with monoiodinated 125I G-17-I (Stadil and Rehfeld, 1972) and using Ab 1296 which is specific for the C-terminal region of G-17 (Dockray and Walsh, 1974). Concentrations of G-17 and G-34 were estimated from elution patterns of the Sephadex columns and expressed in terms of standards of G-17-I and G-34-I respectively.

\section{Results}

GEL FILTRATION PROPERTIES OF MOLECULAR FORMS OF GASTRIN IN SERUM AND TUMOURS Figure 1 shows typical elution profiles obtained when serum and a gastrinoma extract from the same patient were fractionated on columns of Sephadex G50. On these columns standards of pure G-34-I and G-34-II cannot be resolved, but G-17-I and G-17-II can be resolved into two distinct peaks, G-17-II emerging before G-17-I. In the eluates of serum there was one main peak of gastrin immunoreactivity which emerged with an elution volume typical of that for G-34. In addition, there were two minor peaks, the first with the elution volume of G-17-II, the second consistent with G-17-I. The 125I G-17 marker was consistently found to emerge slightly after both pure standard G-17-I and the peak identified as G-17-I in serum. In other serum samples minor peaks of gastrin immunoreactivity corresponding to big big gastrin, component I and G-13 were identified, but together these paaks never accounted for more than $15 \%$ of the 


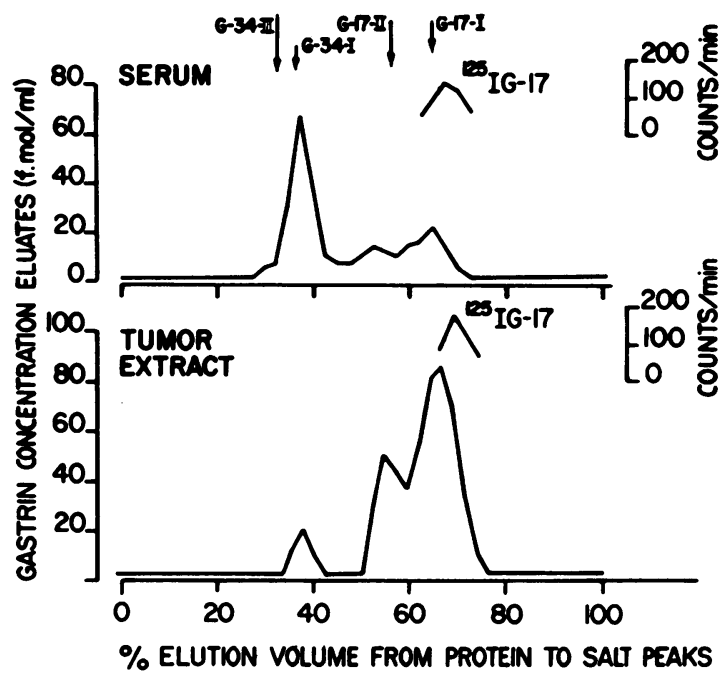

Fig 1 Elution profile of immunoreactive gastrin in a gastrinoma extract and in serum from the same patient taken preoperatively. Arrows indicate elution volumes of standard peptides on this column. Column:

Sephadex G50, $1 \times 100 \mathrm{~cm}$; flow rate: $10 \mathrm{ml} / \mathrm{hr}$; buffer: 0.02M sodium barbital, $\mathrm{pH} 8 \cdot 4$. total gastrin immunoreactivity and their presence and relative concentrations varied from sample to sample.

In the gastrinoma extracts there were again three pcaks of immunoreactivity compatible with G-34 and G-17-II and -I, but unlike serum the G-34 peak was a minor component and the G-17 peaks predominated. The concentrations of G-17 and G-34 in serum and tumour extracts of the patients studied here are given in the table.

RELATIVE CONCENTRATION OF G-34 AND

G-17 IN TUMOURS AND SERUM

A scatter diagram of the concentration of G-17 versus G-34 in 10 serum samples is shown in figure 2a. Because of the wide variation in total gastrin immunoreactivity in serum $(80$ to $301600 \mathrm{fmol} / \mathrm{ml})$, the scale for the concentrations of the molecular forms is logarithmic. The regression line for the points is highly significant $(r=0.979, \mathrm{P}<0.01)$; the mean relative abundance of G-17 [G17/(G17 + G34)] was $0 \cdot 18$, and that of G-34 [G34/(G17 + G34)] was $\mathbf{0 \cdot 8 2}$. There was no significant correlation between the ratio of G-17 to G-34 in serum and the total serum gastrin concentration (fig $2 b, r=0 \cdot 300$ ).

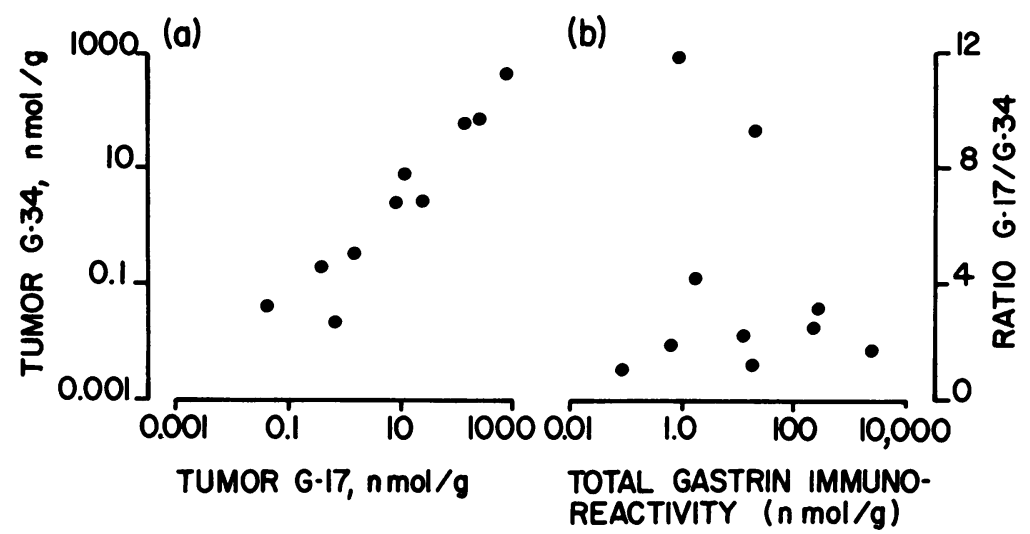

Fig 2a Scatter diagram of $G-17$ concentration versus $G-34$ concentration in fasting serum of 10 Zollinger-Ellison patients. The scales are logarithmic. Concentrations of $G-17$ and $G-34$ calculated from $G-50$ elution profiles. Regression line: log $y=0.964 \log x+0.804(r=$ $0.978, \mathrm{P}>0.01$ ).

Fig $2 \mathrm{~b}$ Scatter diagram of ratio $G-17 / G-34$ versus total gastrin immunoreactivity (on a log scale) in serum of same patients. Regression: $y=0.003 \log x+$ $0 \cdot 35 ; r=0 \cdot 296$.

\begin{tabular}{|c|c|c|c|c|c|}
\hline \multirow[t]{2}{*}{ Patient } & & \multicolumn{2}{|l|}{ Serum } & \multicolumn{2}{|l|}{ Tumour } \\
\hline & & $\mathrm{G}-17(\mathrm{fmol} / \mathrm{ml})$ & $G-34(\mathrm{fmol} / \mathrm{ml})$ & G-17 $(\mathrm{nmol} / \mathrm{g})$ & G-34 $(\mathrm{nmol} / \mathrm{g})$ \\
\hline 2 & & 750 & 8408 & 0.049 & 0.045 \\
\hline 3 & & 78200 & 223446 & $25 \cdot 3$ & $2 \cdot 72$ \\
\hline 4 & & 58 & 132 & 8.9 & 2.7 \\
\hline 5 & & 1656 & 11256 & 262.0 & $77 \cdot 6$ \\
\hline 7 & & 21500 & 99365 & $869 \cdot 0$ & $464 \cdot 0$ \\
\hline 8 & . & 22 & 58 & - & - \\
\hline 9 & & 50 & 379 & - & - \\
\hline 10 & & 43 & 293 & - & - \\
\hline 11 & & - & - & $11 \cdot 1$ & 8.05 \\
\hline 12 & & - & - & $1 \cdot 56$ & 0.38 \\
\hline 13 & & - & - & 0.72 & 0.06 \\
\hline
\end{tabular}

Table Concentrations of $G-17$ and $G-34$ in serum and tumour extracts 


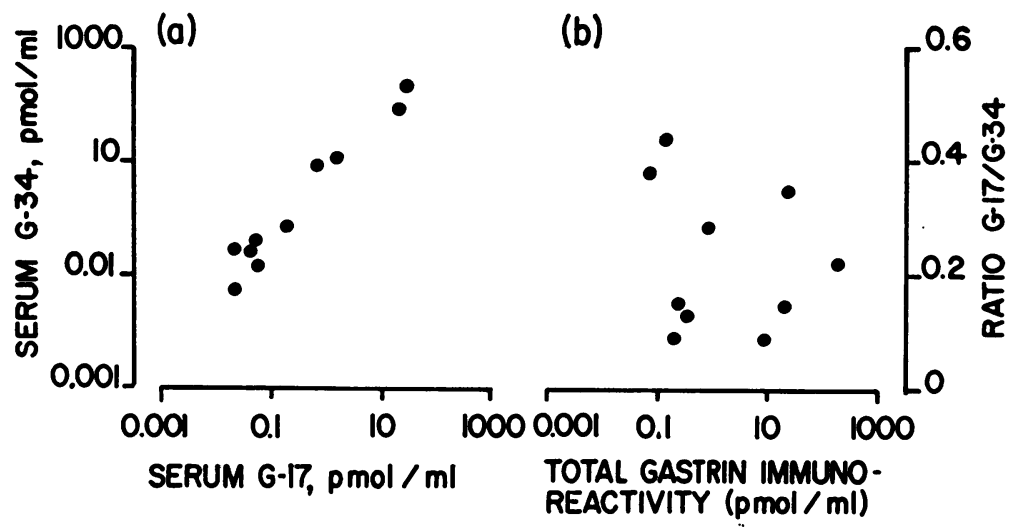

Fig 3a As in fig 2 a but relative concentration of $G-17$ and $G-34$ in gastrinoma extracts of 10 patients. Note seven patients were the same as those represented in figure 2. Regression: $\log y=$ $1.0128 \log x-0.589 ; r=0.946$, $\mathrm{P}<0.01$.

Fig $3 \mathrm{~b}$ As in figure $2 b$ but the ratio of $G-17 / G-34$ versus total gastrin immunoreactivity in gastrinoma extracts. Regression: $y=0.015 \log x+17 \cdot 1 ; r=0 \cdot 19$.
In figure 3 is shown a scatter diagram for G-17 versus G-34 in gastrinoma extracts. Again, there was a significant correlation between concentration of these two molecular forms (fig 3a, $r=0.946$, $P<0.01$ ) but relative abundancies of G-17 and G-34 $(0.73$ and 0.27 respectively) differed markedly from serum. In the tissue, as in the serum, there was no significant correlation between total gastrin immunoreactivity and the ratio of the two principal molecular forms (fig $3 b, r=0 \cdot 189$ ).

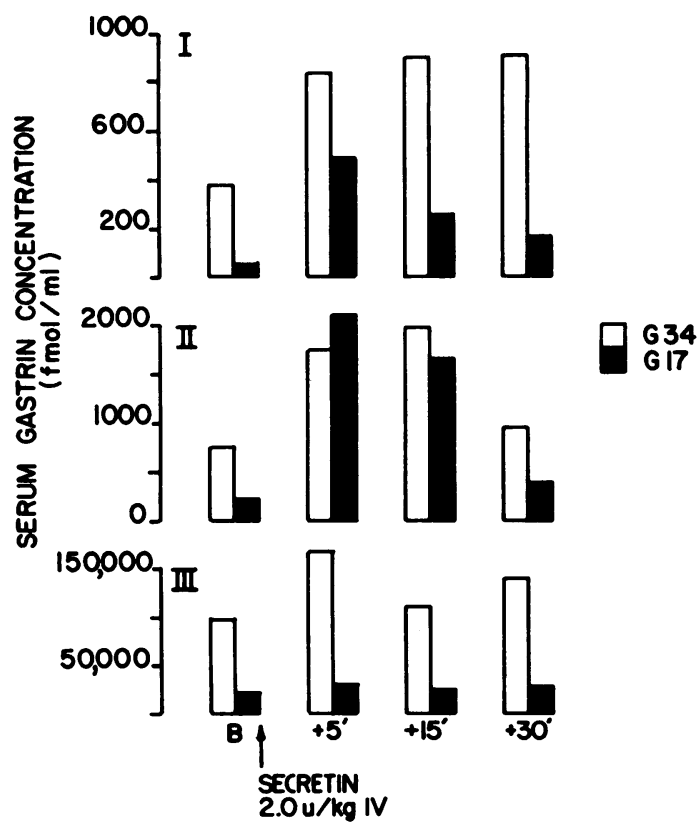

Fig 4 Concentrations of G-17 and G-34 in serum of three patients with the Zollinger-Ellison syndrome at intervals following the administration of pure porcine secretin $2 \cdot 0 \mathrm{u} / \mathrm{kg}$ intravenously.
MOLECULAR FORMS OF GASTRIN IN SERUM AFTER STIMULATION BY SECRETIN

Six of the eight patients who received secretin in this study responded with a prompt increase in serum gastrin concentration. The highest concentration of gastrin was achieved five minutes after the injection and concentration returned to basal over the following 30-to-60-minute period. In the basal state the mean relative proportions of $\mathrm{G}-17$ and $\mathrm{G}-34$ were 0.21 and 0.79 , whereas five minutes after secretin their relative proportions were 0.37 and 0.64 , and the difference was statistically significant $(P<0.05$, paired $t$ test), indicating a preferential secretion of G-17. Typically, the G-17 concentration reached its peak five minutes after secretin and had declined to basal levels by 30 minutes (fig 4, I and II). In contrast, G-34 concentrations tended to peak later, five to 15 minutes, and did not return to basal until 30 to 60 minutes. In one of the six patients who responded to secretin there was no marked increase in $\mathrm{G}-17$ concentration (fig 4, III) although there was a $71 \%$ increase in G-34 concentration; in this patient the relative abundances of $\mathrm{G}-17$ and $\mathrm{G}-34$ in the tumour extract were 0.65 and 0.35 respectively, ie, within the same range as other tumours.

\section{Discussion}

Of the forms of gastrin present in the circulation of gastrinoma patients, only G-34 and G-17 occur in significant concentrations in most patients and are known to be biologically active (Yalow and Berson, 1970; Rehfeld and Stadil, 1973; Walsh, Debas, and Grossman, 1974). The present study confirms previous reports that the main circulating form of gastrin is G-34 and that G-17 is a minor component (Yalow and Berson, 1970; Rehfeld and Stadil, 1973). The presence of both G-34 and G-17 in extracts of tumour tissue has been described (Yalow and 
Berson, 1970), but only a relatively small number of tumour extracts were studied. In the present series, 10 gastrinoma extracts were studied and in every case the predominant form of gastrin was G-17.

In five patients studies were made on the forms of gastrin in serum obtained in the basal fasting state and in serum obtained during surgery. In three cases there were no differences in the relative concentrations of G-17 and G-34, but in two cases serum obtained during surgery contained a much higher proportion of G-17 (about 0.55) than in basal serum (about 0.20).

Taken as a whole there was a highly significant correlation between concentration of G-17 and that of G-34 in both the serum samples $(n=10)$ and tumour extracts $(n=10)$. From this one would anticipate a correlation between the ratio G-17/G-34 in tumour and that in serum. However, in the group of patients for whom both serum and tumour extracts were studied, the ratio of G-17/G-34 in serum versus that in tumour extracts failed to achieve significance $(r=+0.541)$. There were no relationships between the total amount of immunoreactive gastrin in serum or in gastrinomas and the ratio of the two molecular forms. The mean relative proportions of G-17 to G-34 in serum was $0 \cdot 18: 0 \cdot 82$ compared with 0.73:0.27 in tumour extracts. Since the half lives of G-34 and G-17 are different one would not expect to find identical ratios of G-17 and G-34 in the tumour and serum. In the dog, the half life of G-34 is about 15 minutes while that of G-17 is about three minutes (Walsh et al, 1974). Preliminary studies indicate that in man also the half life of G-34 in the circulation is about eight times that of G-17 (Walsh, unpublished data). If the gastrinomas secreted G-34 and G-17 in the same ratio as they were found in extracts, then under steady state conditions (such as occurs in the basal fasting state) the expected ratio in serum can be calculated from the formula:

$$
\frac{\mathrm{G}-17_{\mathrm{g}}}{\mathrm{G}-34_{\mathrm{g}}} \times \frac{\mathrm{G}-17_{\mathrm{t}}}{\mathrm{G}-34_{\mathrm{t}}}=\frac{\mathrm{G}-17_{\mathrm{s}}}{\mathrm{G}-34_{\mathrm{s}}}
$$

where $\mathbf{g}=$ gastrinoma concentration, $\mathbf{s}=$ serum concentration, $t_{\frac{1}{2}}=$ half life.

Thus the predicted relative abundance of G-17 in serum is $\mathbf{0 . 2 5}$ or 1.7 times greater than the observed values. Although the difference in half lives partly explains the widely different ratios of the two molecular forms in tissue and circulation it may not entirely account for the observed ratios. There may be several reasons for this. First, the estimates of half lives of G-17 and G-34, while correct for infusion of pure exogenous hormones administered alone, may not hold when there is a mixture of both G-34 and G-17 and the possibility of interaction between them at degrading sites. Secondly, the procedures used to extract the tumour tissue might either favour the extraction of G-17, or permit the rapid conversion of G-34 to G-17. It should be noted, however, that on repeated extraction of tumour biopsies we found more than $97 \%$ of gastrin immunoreactivity was recovered in the first extract, and that there was over $90 \%$ recovery of 125 I G-34 added to the tumour at the time of extraction. Berson and Yalow (1970) showed that the ratio of G-17/G-34 did not change in repeated extractions of the same tissue. Finally, tumour cells might not secrete G-34 and G-17 in the same ratio that they are stored, ie, there might be preferential secretion of G-34.

Although G-17 constituted only about $20 \%$ of the serum gastrin immunoreactivity its contribution to the biological activity in serum is much greater. In dogs (Walsh et al, 1974) and in man also (Walsh, unpublished) G-17 is about seven times more potent than G-34 in stimulating acid secretion when potencies are expressed in terms of serum concentration. Thus in biological terms G-17 was actually the most important circulating form of gastrin.

The amino acid sequence of G-17 is identical to that of the C-terminal heptadecapeptide portion of G-34, suggesting that the two molecules are synthesized from the same gene and that G-34 is converted to G-17 by cleavage. Gregory and Tracy (1972) reported that the amino terminal portion of G-34 is linked through a Lys-Lys sequence to G-17. This pattern whereby a biosynthetic precursor of a hormone is joined to a smaller, biologically active peptide through two basic amino acids is common to many other protein and peptide hormones, including proinsulin/insulin, proparathyroid hormone/parathyroid hormone, and proglucagon/glucagon (Tager and Steiner, 1974). There is therefore an interesting comparison to be made between the interrelationships of G-34 and G-17 and those of other hormones and their biosynthetic precursors. There are at least two important differences between gastrin and insulin (the hormone which has been most intensively studied from this point of view). Thus, while G-34 has appreciable biological activity, proinsulin has approximately 3 to $5 \%$ of the activity of insulin (Tager and Steiner, 1974). Moreover, G-34 is the predominant form of gastrin in the circulation not only of Zollinger-Ellison patients but also of normal fed subjects (Rehfeld, 1972) while proinsulin comprises only about $20 \%$ of total insulinlike immunoreactivity in the circulation of normal subjects (Tager and Steiner, 1974). It is of interest that in some cases of insulinoma, however, proinsulin may be present in high concentration in the serum although it occurs at low concentrations in the tumour tissues (Yalow and Berson, 1970b). 
Following the injection of secretin there was a prompt departure from the ratios of G-17 to G-34 seen in the basal steady state. In particular, there was a transient but significant increase in the relative proportion of G-17 in the peripheral circulation. The concentration of G-17 returned rapidly to basal levels after peaking about five minutes after secretin. In contrast, the concentration of G-34 rose more slowly and peaked at five to 15 minutes and returned to basal more slowly also. The differences in time course of these responses are consistent with the differences in half lives of G-17 and G-34. The pronounced increase in G-17 relative to G-34 following stimulation by secretin supports the observation that G-17 is the main form of gastrin stored in the tumour cells.

The ratios of G-17 to G-34 in the sera of gastrinoma patients are essentially similar to those in fed normal subjects (Rehfeld, 1973; Yalow and Berson, 1970a). Likewise, the ratios in tumour tissue are similar to those in the antrum (Rehfeld, 1974) although there is a tendency towards a higher proportion of G-34 in tumours. Nevertheless, the overall relationships between the molecular forms of gastrin in tissue and circulation are probably similar irrespective of whether gastrin is derived from gastrinoma or normal antrum. Since G-17 is more potent than G-34 in stimulating acid secretion (Walsh et al, 1974), it is clearly essential that under physiological conditions the relative rates of secretion of these two molecules are carefully controlled. Further studies on the factors regulating the rates of synthesis, conversion, and release of G-34 and G-17 will therefore be of special interest.

We are indebted to Professor R. A. Gregory and Dr H. J. Tracy for gifts of the standard peptides used in this study.

G. J. Dockray was in receipt of a USPHS international postdoctoral fellowship.
This work was supported by grant no. AM 17328 of the NIAMDD to Center for Ulcer Research and Education by USPHS grant no. AM 17294, and by a Veterans Administration senior medical investigatorship (Dr M. I. Grossman).

Bob Weld gave technical assistance.

\section{References}

Berson, S. A., and Yalow, R. S. (1971). Nature of immunoreactive gastrin extracted from tissues of gastrointestinal tract. Gastroenterology, 60, 215-222.

Debas, H. T., Walsh, J. H., and Grossman, M. I. (1974). Pure human minigastrin: secretory potency and disappearance rate. Gut, 15, 686-689.

Dockray, G. J., and Walsh, J. H. (1975). Amino terminal gastrin fragment in serum of Zollinger-Ellison syndrome patients. Gastroenterology, 68, 222-230.

Gregory, R. A. (1974). The gastrointestinal hormones: a review of recent advances. J. Physiol. (Lond.), 241, 1-32.

Gregory, R. A., and Tracy, H. J. (1972). Isolation of two 'big gastrins' from Zollinger-Ellison tumour tissue. Lancet, 2, 797-799.

Gregory, R. A., Tracy, H. J., Agarwal, K. L., and Grossman, M. I. (1969). Aminoacid constitution of two gastrins isolated from Zollinger-Ellison tumour tissue. Gut, 10, 603-608.

Isenberg, J. I., Walsh, J. H., Passaro, E., Jr., Moore, E. W., and Grossman, M. I. (1972). Unusual effect of secretin on serum gastrin, serum calcium, and gastric acid secretion in a patient with suspected Zollinger-Ellison syndrome. Gastroenterology, 62, 626-631.

Rehfeld, J. F. (1972). Three components of gastrin in normal human serum. Gel filtration studies on the molecular size of immunoreactive serum gastrin. Biochem. biophys. Acta (Amst.), 285, 364-372.

Rehfeld, J. F. (1974). What is gastrin? A progress report on the heterogeneity of gastrin in serum and tissue. Digestion, in press.

Rehfeld, J. F., and Stadil, F. (1973). Gel filtration studies on immunoreactive gastrin in serum from Zollinger-Ellison patients. Gut, $14,369-373$.

Stadil, F., and Rehfeld, J. F. (1972). Preparation of ${ }^{125}$ I-labelled synthetic human gastrin I for radioimmunoanalysis. Scand. $J$. clin. Lab. Invest., 30, 361-368.

Tager, H. S., and Steiner, D. F. (1974). Peptide hormones. Ann. Rev. Biochem., 43, 509-538.

Walsh, J. H., Debas, H. T., and Grossman, M. I. (1974). Pure human big gastrin: immunochemical properties, disappearance half time, and acid-stimulating action in dogs. J. clin. Invest., 54, 477-485.

Yalow, R. S., and Berson, S. A. (1970a). Size and charge distinctions between endogenous human plasma gastrin in peripheral bloo and heptadecapeptide gastrins. Gastroenterology, 58, 609-615.

Yalow, R. S., and Berson, S. A. (1970b). Fundamental principle of radioimmunoassay techniques in measurement of hormones. In Rec. Advanc. Endocr., 105, 16-34.

Yalow, R. S., and Berson, S. A. (1972). And now 'big, big' gastrin Biochem. biophys. Res. Commun., 48, 391-395. 